\title{
Single Nucleotide Polymorphisms in a Gene for Translation Initiation Factor (elF4G) of Rice (Oryza sativa) Associated with Resistance to Rice tungro spherical virus
}

\author{
Jong-Hee Lee, ${ }^{1}$ Muhammad Muhsin, ${ }^{2}$ Genelou A. Atienza, ${ }^{2}$ Do-Yeon Kwak, ${ }^{1}$ Suk-Man Kim, ${ }^{2}$ \\ Teresa B. De Leon, ${ }^{2}$ Enrique R. Angeles, ${ }^{2}$ Edgardo Coloquio, ${ }^{2}$ Hiroaki Kondoh, ${ }^{3}$ Kouji Satoh, ${ }^{3,4}$ \\ Rogelio C. Cabunagan, ${ }^{2}$ Pepito Q. Cabauatan, ${ }^{2}$ Shoshi Kikuchi, ${ }^{3}$ Hei Leung, ${ }^{2}$ and II-Ryong Choi ${ }^{2}$ \\ ${ }^{1}$ Department of Functional Crop Science, National Institute of Crop Sciences, Rural Development Administration, \\ 1085 Neidong, Milyang, Gyeongnam, 627-803, Republic of Korea; ${ }^{2}$ Plant Breeding, Genetics, and Biotechnology Division, \\ International Rice Research Institute, DAPO Box 7777, Metro Manila, Philippines; ${ }^{3}$ Plant Genome Research Unit, Division \\ of Genome and Biodiversity Research, National Institute of Agrobiological Sciences, Kan'non dai 2-1-2 Tsukuba, Ibaraki \\ 305-8602, Japan; ${ }^{4}$ Research Team for Vector-borne Plant Pathogens, National Agricultural Research Center, Tsukuba, \\ Ibaraki 305-8666, Japan.
}

Submitted 8 July 2009. Accepted 15 September 2009.

Rice tungro disease (RTD) is a serious constraint to rice production in South and Southeast Asia. RTD is caused by Rice tungro spherical virus (RTSV) and Rice tungro bacilliform virus. Rice cv. Utri Merah is resistant to RTSV. To identify the gene or genes involved in RTSV resistance, the association of genotypic and phenotypic variations for RTSV resistance was examined in backcross populations derived from Utri Merah and rice germplasm with known RTSV resistance. Genetic analysis revealed that resistance to RTSV in Utri Merah was controlled by a single recessive gene (tsv1) mapped within an approximately $200-\mathrm{kb}$ region between 22.05 and 22.25 Mb of chromosome 7. A gene for putative translation initiation factor $4 \mathrm{G}\left(\mathrm{eIF} 4 \mathrm{G}^{t s v l}\right.$ ) was found in the tsv1 region. Comparison of eIF4G ${ }^{t s v l}$ gene sequences among susceptible and resistant plants suggested the association of RTSV resistance with one of the single nucleotide polymorphism (SNP) sites found in exon 9 of the gene. Examination of the SNP site in the eIF4G ${ }^{t s v}$ gene among various rice plants resistant and susceptible to RTSV corroborated the association of SNP or deletions in codons for Val ${ }^{1060-1061}$ of the predicted eIF4G ${ }^{t s v I}$ with RTSV resistance in rice.

Rice tungro disease (RTD) is one of the most serious diseases of rice in South and Southeast Asia. The symptoms are stunting and yellow or yellow-orange discoloration of leaves. Panicle exertion is delayed and often incomplete, and panicles are short and often sterile. RTD is caused by Rice tungro spherical virus (RTSV) and Rice tungro bacilliform virus (RTBV), which are transmitted by green leafhoppers (GLH) such as Nephotettix virescens Distant (Hibino 1983). RTSV is a singlestranded RNA virus belonging to the family Sequiviridae, whereas RTBV is a double-stranded DNA virus belonging to the family Caulimoviridae (Fauquet et al. 2005). RTSV and RTBV have different functions in the development of RTD in

Corresponding author: Il-Ryong Choi; E-mail: ichoi@ cgiar.org

* The $\boldsymbol{e}$-Xtra logo stands for "electronic extra" and indicates that two supplementary figures and one supplementary table are published online. the field. RTSV plays the role of a helper virus for insect transmission of RTBV (Hibino 1983). RTSV alone does not cause any distinctive symptoms, except mild stunting in some rice cultivars (Hibino 1983, Cabauatan et al. 1993). Infection of rice plants with RTBV, however, results in severe symptoms, which are accentuated by co-infection with RTSV (Hibino 1983).

Because of the wide distribution of RTD in tropical Asia, the introduction of resistance to RTD into rice cultivars has been an important objective of rice breeding in the region. Because two tungro viruses and an insect vector are involved in the development of RTD in the field, protection of rice plants from RTD can be achieved by genes with resistance to one of the virus-vector (disease) components. Resistance to the insect vector of RTD has been commonly introduced into rice cultivars and has contributed to a reduction in RTD in affected areas (Angeles and Khush 2000), although some vector-resistant cultivars succumbed to tungro after a few years of intensive cultivation (Dahal et al. 1990). Extensive evaluation of rice germplasm collections identified potential genetic resources for tungro virus resistance (Hibino et al. 1988, 1990). Several rice germplasm sources resistant to tungro viruses have been used to improve rice cultivars in RTD-endemic areas (Cabunagan et al. 1999; Khush et al. 2004), although a distinction between resistance to GLH and to tungro viruses in some rice genotypes is still unclear (Sebastian et al. 1996; Shibata et al. 2007; Zenna et al. 2008).

More than a dozen viruses were reported to infect rice plants (Hibino 1996). Genome locations and the identities of genes associated with resistance to major rice viruses have been characterized. Loci linked to resistance to RTSV (Sebastian et al. 1996), Rice stripe virus (RSV) (Hayano-Saito et al. 2000; Maeda et al. 2006; Wu et al. 2009), and Rice yellow mottle virus (RYMV) (Boisnard et al. 2007) were mapped in the rice genome. A gene for a translation initiation factor (eIF4(iso)4G) was reported to be responsible for recessive resistance to RYMV (Albar et al. 2006). A rice mutant with a disrupted gene for an NAC-domain (a domain characterized by NAM, ATAF1, 2, and CUC2 transcription factors) (Olsen et al. 2004) protein was resistant to Rice dwarf virus (RDV), suggesting that the gene is required for replication of RDV (Yoshii et al. 2009). 
Two rice germplasm accessions of Utri Merah (International Rice Germplasm Collection [IRGC] accession numbers 16680 [UM80] and 16682 [UM82]) are resistant to both RTSV and RTBV (Shahjahan et al. 1990; Ebron et al. 1994; Imbe et al. 1995; Azzam et al. 2001; Azzam and Chancellor 2002; Encabo et al. 2009). Genetic studies revealed that RTSV resistance of UM80 and UM82 is controlled by one or two recessive genes (Ebron et al. 1994; Imbe et al. 1995; Azzam et al. 2001). An allelism test for RTSV resistance of UM80 with other rice cultivars showed that at least one of the genes associated with RTSV resistance is the same among UM80 and two other cultivars, Utri Rajapan and Pankhari 203 (Ebron et al. 1994).

In a previous report, we showed that the resistance trait in Utri Merah for RTSV and for RTBV is inherited separately (Encabo et al. 2009). However, genes conferring resistance to tungro viruses in Utri Merah have not been defined yet. Therefore, to identify the gene or genes associated with RTSV resistance in Utri Merah, we determined the locus linked to RTSV resistance in UM82 and examined the presence of any probable allelic variations associated with RTSV resistance within the locus. Our results showed that RTSV resistance in UM82 is conferred by a single recessive gene located between 22.05 and 22.25 Mb of chromosome 7, and that single-nucleotide polymorphisms (SNP) observed in a gene encoding putative translation initiation factor $4 \mathrm{G}(\mathrm{eIF} 4 \mathrm{G})$ are strongly associated with reactions to RTSV among rice genotypes.

\section{RESULTS}

RTSV resistance is controlled by a single recessive gene.

Backcross line TW16 $\left(\mathrm{BC}_{5} \mathrm{~F}_{8}\right)$ was developed by serial backcrosses of the RTSV-resistant donor cv. Utri Merah (accession number 16682, UM82) to the RTSV-susceptible recurrent parent Taichung Native 1 (TN1) (Fig. 1) (Imbe et al. 1995). To confirm the resistance of TW16 to tungro viruses, TW16 was inoculated with RTSV and RTBV via GLH. RTSV was not detected in TW16 by enzyme-linked immunosorbent assay (ELISA) with RTSV-specific antibody, while the titer of RTBV in TW16 was significantly lower than that in TN1 at 14 to 21 days postinoculation (dpi) (Encabo et al. 2009). TW16 was backcrossed again to $\mathrm{TN} 1$ and the resultant $\mathrm{BC}_{6} \mathrm{~F}_{3}$ population, consisting of $211 \mathrm{~F}_{3}$ families of TN1/TW16, was examined for reactions to RTSV infection. Individual families were classified as resistant or susceptible based on the rate of infection with RTSV (discussed below). The segregation ratio among $\mathrm{F}_{3}$ families was consistent with the expected 1:2:1 ratio, suggesting the inheritance of a recessive gene for resistance (Table 1). One of the RTSV-resistant $\mathrm{BC}_{6}$ lines from the TN1/TW16 cross, TW16-1120, was then crossed with RTSV-susceptible cv. Unkwang (Fig. 1). The $\mathrm{F}_{2}$ plants of Unkwang/TW16-1120 were evaluated for reactions to RTSV. The segregation ratio among the $\mathrm{F}_{2}$ plants fit a 1:3 ratio. Together, these results indicated that RTSV resistance from UM82 is controlled by a single recessive gene.

\section{RTSV resistance is mapped} within a 200-kb region on chromosome 7 .

To identify genome introgressions from UM82 in TW16, genotypic polymorphisms among TN1, UM82, and TW16 were examined with simple sequence repeat (SSR) markers. Among 131 SSR markers examined, 24 showed polymorphisms between TN1 and Utri Merah (Table 2). Examination of the genome of TW16 with the polymorphic markers showed two introgression segments in TW16 from UM82: i) near the end

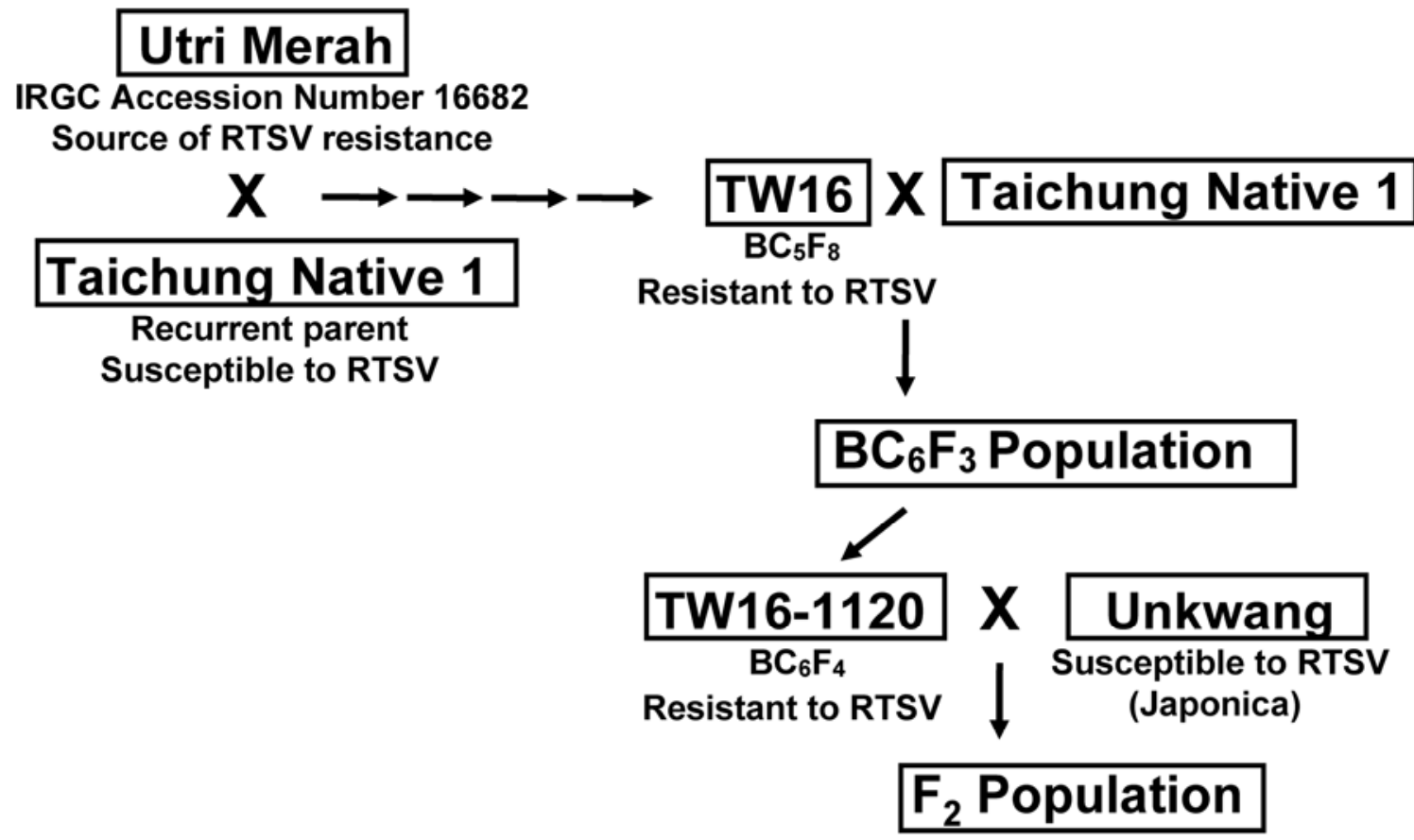

Fig. 1. Development and relationship of plant materials used in this study.

Table 1. Segregation of reactions to Rice tungro spherical virus (RTSV) infection in plant populations derived from RTSV-resistant TW16

\begin{tabular}{lccccccc}
\hline & \multicolumn{9}{c}{ Reaction to RTSV } & & \\
\cline { 2 - 6 } Cross combination & Total & Resistant & Segregating & Susceptible & Expected ratio & $\chi^{2}$ Value & Probability \\
\hline TN1/TW16 $\left(\mathrm{F}_{3}\right.$ families $)$ & 211 & 56 & 108 & 47 & $1: 2: 1$ & 0.87 & 0.65 \\
Unkwang/TW16-1120 $\left(\mathrm{F}_{2}\right.$ plants $)$ & 117 & 33 & $\ldots$ & 84 & $1: 3$ & 0.33 & 0.56 \\
\hline
\end{tabular}


of the short arm of chromosome 6, as indicated by markers RM170, RM190, and RM435; and ii) in the middle of the long arm of chromosome 7, as indicated by markers RM10, RM70, RM180, and RM336. The presence of introgressed segments in chromosomes 6 and 7 was further examined using 20 representative (10 RTSV-resistant and 10 susceptible) $\mathrm{BC}_{6}$ lines from the TN1/TW16 cross. Only the introgressed segment in chromosome 7 co-segregated with RTSV resistance (Table 3).
Linkage between RTSV resistance and SSR markers on chromosome 7 was then examined using $117 \mathrm{~F}_{2}$ plants derived from the Unkwang/TW16 cross. The result indicated that the RTSV resistance gene ( $t s v 1)$ was linked to the markers located near position $22 \mathrm{Mb}$ of chromosome 7 (Table 4). Among 117 $\mathrm{F}_{2}$ plants examined, recombination between RM336 and resistance was observed in two plants (recombination value $1.7 \%$ ) and recombination at RM455 was observed in one plant (re-

Table 2. Genotypic polymorphisms among recurrent parent Taichung Native 1 (TN1), resistance donor Utri Merah (UM82), and backcross line TW16 examined by simple sequence repeat markers

\begin{tabular}{lccc}
\hline Chromosome & $\begin{array}{c}\text { No. of markers } \\
\text { examined }\end{array}$ & $\begin{array}{c}\text { No. of markers polymorphic } \\
\text { between TN1 and UM82 }\end{array}$ & Markers indicating introgressions from UM82 to TW16 \\
\hline 1 & 10 & 1 & $\ldots$ \\
2 & 15 & 3 & $\ldots$ \\
3 & 16 & 3 & $\ldots$ \\
4 & 11 & 3 & $\ldots$ \\
5 & 18 & 0 & $\ldots$ \\
6 & 6 & 3 & RM170, RM190, RM435 \\
7 & 14 & 6 & $\ldots$ \\
8 & 11 & 3 & $\ldots$ \\
9 & 9 & 0 & $\ldots$ \\
10 & 5 & 1 & $\ldots$ \\
11 & 5 & 0 & $\ldots$ \\
12 & 11 & 1 & $\ldots$ \\
\hline
\end{tabular}

Table 3. Reactions to Rice tungro spherical virus (RTSV) and marker genotypes of representative $\mathrm{BC}_{6} \mathrm{~F}_{3}$ families developed from TW16 and TN1

\begin{tabular}{|c|c|c|c|c|}
\hline \multirow[b]{2}{*}{ Parent $/ F_{3}$ family $^{x}$} & \multirow[b]{2}{*}{ Reaction to RTSV } & \multirow[b]{2}{*}{ Infection percentage $^{\mathrm{z}}$} & \multicolumn{2}{|c|}{ Marker genotype $^{w}$} \\
\hline & & & RM435 & RM336 \\
\hline \multicolumn{5}{|l|}{ Parent } \\
\hline TN1 & $\mathrm{S}$ & 100.0 & $\mathrm{a}$ & $\mathrm{a}$ \\
\hline UM82 & $\mathrm{R}$ & 0.0 & $\mathrm{~b}$ & $\mathrm{~b}$ \\
\hline TW16 & $\mathrm{R}$ & 0.0 & $\mathrm{~b}$ & $\mathrm{~b}$ \\
\hline \multicolumn{5}{|l|}{$\mathrm{BC}_{6} \mathrm{~F}_{3}$ family } \\
\hline TW16-1006 & $\mathbf{R}$ & 0.0 & b & b \\
\hline TW16-1007 & $\mathbf{R}$ & 0.0 & b & b \\
\hline TW16-1020 & $\mathbf{R}$ & 0.0 & a & b \\
\hline TW16-1025 & $\mathbf{R}$ & 0.0 & c & b \\
\hline TW16-1029 & $\mathbf{R}$ & 0.0 & b & b \\
\hline TW16-1042 & $\mathbf{R}$ & 0.0 & c & b \\
\hline TW16-1044 & $\mathbf{R}$ & 0.0 & b & b \\
\hline TW16-1120 & $\mathbf{R}$ & 0.0 & c & b \\
\hline TW16-1128 & $\mathbf{R}$ & 0.0 & c & b \\
\hline TW16-1209 & $\mathbf{R}$ & 0.0 & c & b \\
\hline TW16-1034 & Seg & 40.0 & $\mathrm{~b}$ & $\mathrm{c}$ \\
\hline TW16-1216 & Seg & 40.0 & $\mathrm{c}$ & $\mathrm{c}$ \\
\hline TW16-1136 & Seg & 46.7 & $\mathrm{~b}$ & $\mathrm{c}$ \\
\hline TW16-1147 & Seg & 46.7 & $\mathrm{c}$ & $\mathrm{c}$ \\
\hline TW16-1108 & Seg & 53.3 & $\mathrm{a}$ & c \\
\hline TW16-1026 & Seg & 60.0 & $\mathrm{~b}$ & $\mathrm{c}$ \\
\hline TW16-1207 & Seg & 60.0 & $\mathrm{a}$ & $\mathrm{c}$ \\
\hline TW16-1208 & Seg & 60.0 & $\mathrm{c}$ & a \\
\hline TW16-1224 & Seg & 66.7 & $\mathrm{~b}$ & c \\
\hline TW16-1150 & Seg & 73.3 & $\mathrm{~b}$ & c \\
\hline TW16-1214 & Seg & 73.3 & $\mathrm{c}$ & $\mathrm{a}$ \\
\hline TW16-1002 & $\mathbf{S}$ & 80.0 & c & c \\
\hline TW16-1048 & $\mathbf{S}$ & 80.0 & c & c \\
\hline TW16-1072 & $\mathbf{S}$ & 80.0 & c & c \\
\hline TW16-1123 & $\mathbf{S}$ & 80.0 & c & $\mathbf{a}$ \\
\hline TW16-1043 & $\mathbf{S}$ & 93.3 & c & $\mathbf{a}$ \\
\hline TW16-1049 & $\mathbf{S}$ & 93.3 & c & a \\
\hline TW16-1104 & $\mathbf{S}$ & 93.3 & c & $\mathbf{a}$ \\
\hline TW16-1107 & $\mathbf{S}$ & 93.3 & c & a \\
\hline TW16-1008 & $\mathbf{S}$ & 100.0 & c & a \\
\hline TW16-1012 & $\mathbf{S}$ & 100.0 & b & $\mathbf{a}$ \\
\hline
\end{tabular}

${ }^{\mathrm{w}} \mathrm{RM} 435=0.53 \mathrm{Mb}$ on chromosome 6 and RM336 = 21.8 Mb on chromosome 7; a, homozygous-susceptible genotype; b, homozygous-resistant genotype; and c, heterozygous genotype.

${ }^{\mathrm{x}}$ In all, 10 susceptible and 10 resistant $\mathrm{BC}_{6} \mathrm{~F}_{3}$ families examined to test the association of RTSV resistance with the introgression in chromosome 6 (represented by marker genotypes of RM435) and that in chromosome 7 (represented by marker genotypes of RM336) are indicated in bold.

${ }^{y}$ Reactions were classified as S, susceptible to RTSV (infection rate $\geq 80 \%$ ); Seg, segregating for reaction to RTSV (21 to $79 \%$ ); and R, resistant ( $\leq 20 \%$ ).

${ }^{\mathrm{z}}$ Infection rate $=$ (number of plants infected with RTSV/number of plants inoculated $) \times 100$. 
combination value $0.9 \%$ ). Thus, tsvl was inferred to be between RM336 and RM455. Based on the physical locations of RM336 and RM455 in the japonica rice Nipponbare genome, $t s v 1$ is located between 21.8 and $22.3 \mathrm{Mb}$ of chromosome 7 .

To precisely determine the location of $t s v 1$, a larger number of $F_{2}$ plants derived from the Unkwang/TW16 cross were examined for the association between reactions to RTSV infection and markers located between RM336 and RM455. Inoculation of RTSV to rice plants is mediated by GLH; thus, evaluation of rice plants for RTSV infection sometimes results in a false resistance reaction due to inadequate inoculation of RTSV by GLH. To avoid such a false resistance reaction, precise mapping of $t s v 1$ was conducted using RTSV-susceptible $\mathrm{F}_{2}$ plants from the cross between Unkwang and TW16-1120. Among $915 \mathrm{~F}_{2}$ plants from this cross evaluated for reactions to RTSV infection, 455 were found to be highly susceptible (optical density at $405 \mathrm{~nm}>1.0$ by ELISA at $21 \mathrm{dpi}$ ). Two SSR markers (RM455 and RM336) flanking the $t s v 1$ gene (Table 4) were used to detect recombination between the markers and tsv1 from the 455 RTSV-susceptible plants. Examination with

Table 4. Linkage relationship between Rice tungro spherical virus (RTSV) resistance (tsv1) and simple sequence repeat (SSR) markers on chromosome 7 in the $\mathrm{F}_{2}$ population derived from a cross between Unkwang and TW16

\begin{tabular}{|c|c|c|c|c|c|c|c|c|}
\hline \multirow{2}{*}{$\frac{\text { Locus }}{\text { A(a) B(b) }}$} & \multicolumn{6}{|c|}{ Segregation mode ${ }^{\mathrm{z}}$} & \multirow[b]{2}{*}{ Recombination value (\%) } & \multirow[b]{2}{*}{ Physical location (Mb) } \\
\hline & AAB- & AAbb & AaB- & Aabb & aaB- & aabb & & \\
\hline RM21677-tsv1 & 23 & 1 & 55 & 5 & 10 & 23 & 13.8 & 19.3 \\
\hline RM21760 - tsv1 & 28 & 0 & 56 & 2 & 4 & 27 & 5.1 & 19.6 \\
\hline $\mathrm{RM} 336-t s v 1$ & 30 & 0 & 56 & 0 & 2 & 29 & 1.7 & 21.8 \\
\hline $\mathrm{RM} 455-t s v 1$ & 28 & 0 & 59 & 0 & 1 & 29 & 0.9 & 22.3 \\
\hline RM5623 - tsv1 & 26 & 0 & 60 & 2 & 2 & 27 & 3.4 & 23.0 \\
\hline $\mathrm{RM} 234-t s v 1$ & 36 & 2 & 45 & 10 & 7 & 17 & 16.2 & 25.5 \\
\hline
\end{tabular}

${ }^{\mathrm{z}}$ A (a) represents SSR marker genotype. AA: homozygous for Unkwang allele, Aa: heterozygous, aa: homozygous for TW16 allele. B (b) represents phenotype for $t s v 1$, B-(BB or Bb): susceptible to RTSV, bb: resistant to RTSV.

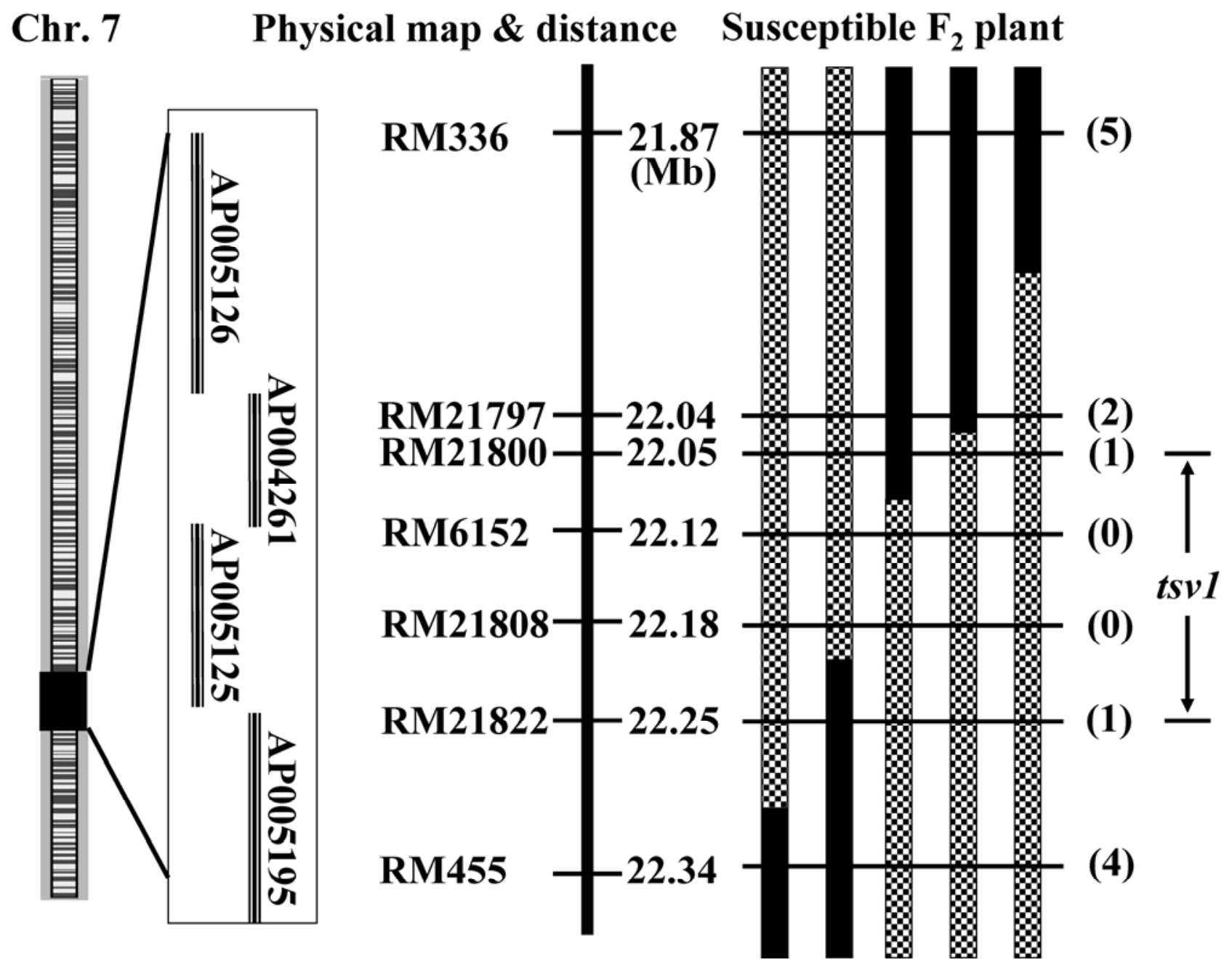

Fig. 2. Physical map of the tsv1 locus. Physical positions of BAC clones AP005126 to AP005195 on chromosome 7 based on the Nipponbare genome are shown at left. Physical positions of simple sequence repeat markers (RM336 to RM455) used for mapping of $t s v 1$ are shown in middle. Black and checkered bars at right represent some genotypes of Rice tungro spherical virus-susceptible $\mathrm{F}_{2}$ plants from the TW16-1120/Unkwang cross with recombination at $t s v 1$. Black and checkered areas represent genomes from TW16-1120 (UM82) and Unkwang, respectively. The numbers in parentheses indicate that the recombinants occurred at the corresponding marker loci derived in the susceptible $\mathrm{F}_{2}$ plants. Physical positions of BAC clones and markers are based on information available from the GRAMENE database. 
RM336 identified five recombination events between the marker and $t s v 1$ gene on one side, and examination with RM455 detected four recombination events between the marker and $t s v 1$ on the other side (Fig. 2). Five additional markers-RM21797, RM21800, RM6152, RM21808, and RM21822-which are located between RM336 and RM455, were used to evaluate the frequency of recombination surrounding $t s v 1$. Examination with markers RM21800 and RM21822 identified two recombination events, one each with the respective markers. No recombination was detected with RM6152 and RM21808, suggesting that these markers were tightly linked to $t s v l$ (Fig. 2). Thus, based on the physical map of japonica rice Nipponbare, tsv1 was defined by RM21800 and RM21822 located in the BAC clones AP004261 and AP005195, respectively. The physical distance between the two markers is approximately $200 \mathrm{~kb}$.

SNP in the eIF4G gene at $t s v 1$ are associated with RTSV resistance.

The $200-\mathrm{kb}$ (22.05 to $22.25 \mathrm{Mb}$ ) region of chromosome 7 where tsvl was mapped contains at least 36 gene models according to the Rice Genome Annotation Osal database. The genes predicted in the region include those for cellulose synthases, kinases, cyclin, translation initiation factor $4 \mathrm{G}$, Rieske $\mathrm{Fe}-\mathrm{S}$ precursor protein, Phox/Bem1p (PB1) domain-containing protein, transposon-related proteins, F-box domain-containing proteins, and various unknown or hypothetical proteins. To identify genes in the region whose expression levels are affected by RTSV infection, the gene expression levels of TN1 and TW16 infected with RTSV were examined by an oligonucleotide microarray (Satoh et al. 2007). The microarray contains probes for 30 genes located within the $t s v 1$ region $(22.05$ to $22.25 \mathrm{Mb}$ of chromosome 7). Comparison of gene expression levels between mock-inoculated and RTSV-infected plants at 6, 9, and 15 dpi indicated that, among the 30 genes examined, only the expression of cyclin was activated in both TN1 (average 1.6-fold among three repeated experiments) and TW16 (average 2.0fold) by RTSV infection at 9 dpi (Supplementary Table 1).

The region of $t s v 1$ contains a gene (LOC_Os7g36940) (Fig. 3) encoding an eIF4G. (eIF4G ${ }^{t s v l}$ hereafter). We considered the gene for eIF4 $\mathrm{G}^{t s v l}$ to be a promising candidate gene for RTSV resistance in UM82, because members of the eIF4G gene family are known to be involved in recessive virus resistance in plants

\begin{tabular}{|c|c|c|}
\hline Chr 7 & \multicolumn{2}{|c|}{$22.26 \mathrm{Mb}$} \\
\hline AP004261 & & AP005195 \\
\hline & $\mathrm{AP} 005125(151 \mathrm{~kb})$ & \\
\hline
\end{tabular}

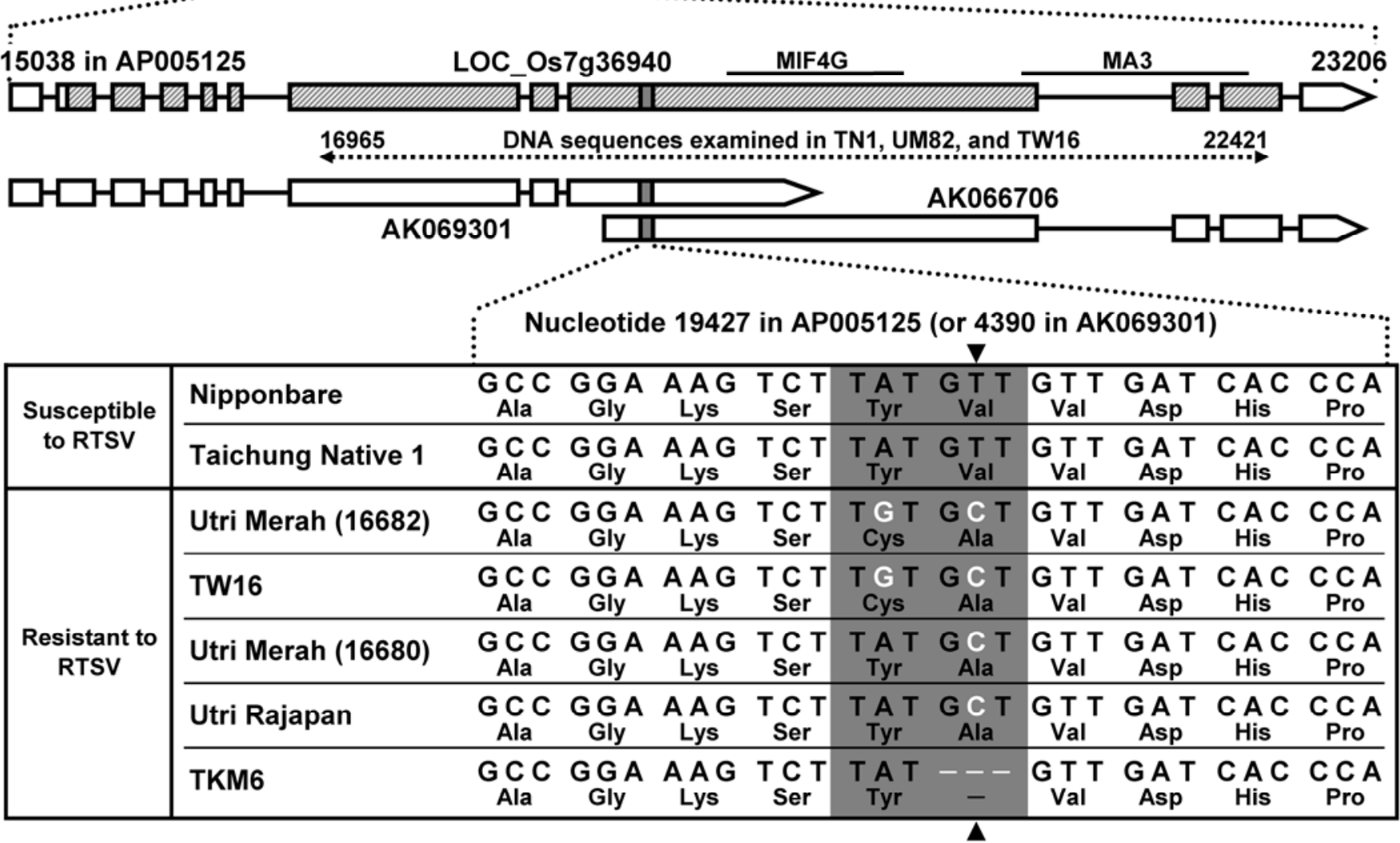

Amino acid 1060 in translated AK069301

Fig. 3. Position and structure of the eIF4G ${ }^{t s v l}$ gene (LOC_Os7g3690) and single-nucleotide polymorphisms (SNPs) found in exon 9 of the gene from Rice tungro spherical virus (RTSV)-susceptible and -resistant plants. Physical positions of BAC clones (AP004261, AP005125, and AP005195) on chromosome 7 are described on top of the figure. The gray box in AP005125 is the approximate position of AP005125. LOC_Os7g36940 is the gene model for eIF4G $\mathrm{G}^{t s v l}$ based on the Nipponbare genome. Boxes and lines indicate predicted exons and introns of the gene. Locations of MIF4G and MA3 domains characteristic of eIF4G are indicated above the gene model. Shadowed area in the gene model represents predicted coding sequences for eIF4G ${ }^{t s v l}$. AK069301 and AK066707 are cDNA molecules isolated from Nipponbare. Dotted line indicates the region where DNA sequences were determined in TN1, TW16, and UM82. Gray boxes in the gene model and cDNA molecules indicate the position of SNP site examined among RTSV-resistant and -susceptible plants. The table at the bottom shows the nucleotide sequences around SNP ${ }^{4390}$ site in various plants. The nucleotide sequence in TKM6 corresponding to the nucleotides at positions 19,423 to 19,431 of AP05125 could be TAT-GTT-- - - or TAT-- - --GTT. 
(Yoshii et al. 2004; Albar et al. 2006). In particular, the eIF4G ${ }^{t s v l}$ gene is an ortholog of the Arabidopsis thaliana eIF4G gene at the cum 2 locus (eIF4G ${ }^{\text {cum } 2}$ hereafter) conferring resistance to Turnip crinkle virus (TCV) and Cucumber mosaic virus (CMV) (Boisnard et al. 2007; Yoshii et al. 2004). Although several cDNA molecules such as AK069301 and AK066706 (Rice FullLength cDNA Consortium 2003) mapped to LOC_Os7g36940 were isolated from rice, cDNA molecules encompassing the entire length of LOC_Os7g36940 have not been identified (Fig. $3)$. The result of microarray analysis indicated that the expression level of the eIF4G ${ }^{t s v l}$ gene was not affected by RTSV infection in TN1 or TW16. We also compared the expression levels of the eIF4 $\mathrm{G}^{t s v l}$ gene between TN1 and TW16 by reverse-transcription polymerase chain reaction (PCR) using primers specific for AK069301 and AK066706 but did not observe a significant difference in the expression of the gene between the two genotypes (data not shown).

To examine whether any sequence variations in the eIF4G ${ }^{t s v l}$ gene are associated with a difference in reactions of plants to RTSV infection, we compared the DNA sequences of the eIF4G ${ }^{t s v l}$ gene from TN1, UM82, and TW16. Approximately 5.5 $\mathrm{kb}$ of eIF4 $\mathrm{G}^{t s v l}$ genomic DNA sequences in TN1, UM82, and TW16, corresponding to nucleotide positions from 16965 to 22421 in BAC clone AP005125 of the Nipponbare genome, were determined (Fig. 3; Supplementary Fig. 1). Alignment of the gene sequences from the three genotypes with the corresponding sequences in the Nipponbare genome, which is susceptible to RTSV, revealed 13 SNP and two deletion sites within the $5.5-\mathrm{kb}$ sequence of the eIF4G ${ }^{t s v l}$ gene. Nucleotides in 10 of the 13 SNP sites and one of the two deletion sites were identical among TN1 (susceptible to RTSV), UM82 (resistant), and TW16 (resistant) but were different in Nipponbare (susceptible). One of the remaining three SNP sites was located in an intron of the gene and was different between TN1 and Nipponbare. Thus, 12 of the 15 SNP or deletion sites did not seem to be associated with RTSV resistance. Another deletion site (nucleotide positions from 21317 to 21319 of AP005125), which was mapped within an intron, was different among TN1, UM82, and Nipponbare. Two of the remaining SNP were found within exon 9 of the gene at nucleotide positions 4387 ( $\mathrm{SNP}^{4387}$ hereafter) and 4390 (SNP ${ }^{4390}$ hereafter) of AK069301 (Fig. 3). The sequences at these SNP sites were TAT-GTT $\left(\mathrm{Tyr}^{1059}-\mathrm{Val}^{1060}\right.$ in translated AK069301) in RTSV-susceptible Nipponbare and TN1. In contrast, the sequence variants in RTSV-resistant UM82 and TW16 were TGTT-GㅡT $\left(\mathrm{Cys}^{1059}-\mathrm{Ala}^{1060}\right.$ ), suggesting that these SNP may be associated with RTSV resistance.

To substantiate the association of $\mathrm{SNP}^{4387}$ and $\mathrm{SNP}^{4390}$ with RTSV resistance, we examined nucleotide sequences at the corresponding SNP sites in other rice genotypes. First, the SNP sites of three other RTSV-resistant plants-UM82, Utri Rajapan (Ebron et al. 1994), and TKM6 (Azzam et al. 2001)were examined. RTSV resistance of UM80 and Utri Rajapan is reported to be controlled by the same allele of a single gene (Ebron et al. 1994). Sequencing at the SNP sites showed that the nucleotide at $\mathrm{SNP}^{4390}$ site in UM82 and Utri Rajapan (GCET encoding $\mathrm{Ala}^{1060}$ ) was different from that in Nipponbare. It appeared that three nucleotides (GTT) at $\mathrm{SNP}^{4390}$ site encoding $\mathrm{Val}^{1060}$ were deleted in TKM6. However, because there are two consecutive Val residues at amino acid positions $1060\left(\mathrm{Val}^{1060}\right)$ and 1061 ( $\mathrm{Val}^{1061}$ ), we were not able to determine which Val residue was deleted in eIF4G ${ }^{t s v l}$ of TKM1 (Fig. 3). Subsequently, we examined nucleotide sequences at the SNP sites in available genotypes with a known reaction to tungro viruses (Table 5). These include indica and japonica rice cultivars (Azucena, Pokali, Swarna, Unkwang, BR11, IR22, IR24, IR46, and IR64), an RSV-resistant japonica cultivar (Dongjin), UM80-derived RTD-resistant cultivars (Matatag 1 and Matatag 2), an Oryza rufipogon-derived RTD-resistant cultivar (Matatag 9), individual plants of $23 \mathrm{BC}_{6}$ lines from the UM82/TN1 cross, individual plants of 11 UM80-derived lines (susceptible parents IR1561-228-3-3, IR61009-37-2-1-2, or IR44624-1271-2-2-3), and individual plants of 5 Utri Rajapan-derived lines (susceptible parents IR1561-228-3 or IR24). The results of nucleotide sequencing revealed that all plants susceptible to RTSV have the susceptible (S)-type allele (TAT [Tyr $\left.{ }^{1059}\right]-G T T$ $\left[\mathrm{Val}^{1060}\right]$ ) identical to that found in Nipponbare, while those resistant to RTSV have one of the three non-S-allele types; namely, UM-type substitution (TGT $\left[\mathrm{Cys}^{1059}\right]-\mathrm{GCT}\left[\mathrm{Ala}^{1060}\right]$ ), UR-type substitution (TAT [Tyr $\left.{ }^{1059}\right]-G \underline{C T}\left[\right.$ Ala $\left.^{1060}\right]$ ), or TKM6type three-nucleotide deletion (TAAT $\left[\mathrm{Tyr}^{1059}\right]-{ }^{10}$ - --GTT $\left[\mathrm{Val}^{1061}\right]$ or TAT $\left.\left[\mathrm{Tyr}^{1059}\right]-\mathrm{GTT}\left[\mathrm{Val}^{1060}\right]----\right)$. Examination of $\mathrm{SNP}^{4387}$ and $\mathrm{SNP}^{4390}$ among the individual plants of $\mathrm{BC}_{6}$ lines from the UM82/TN1 cross indicated that the phenotypes of the individual plants for RTSV infection cosegregated with the corresponding allele types. The resistant plants of UM80- and UR-derived lines were found to have either UM- or UR-allele types. Collectively, the results of a sequence survey in the eIF $4 G^{t s v l}$ gene suggested that the reactions of plants to RTSV infection are associated with the $\mathrm{SNP}^{4390}$ site, and the resultant deletion or substitution of Val ${ }^{1060-1061}$ in eIF4G ${ }^{t s v l}$.

\section{DISCUSSION}

Resistance originating from Utri Merah has been used for breeding rice cultivars, some of which were already deployed in RTD-affected areas (Cabunagan et al. 1999; Azzam and

Table 5. Alleles in the gene for eIF $4 \mathrm{G}$ at $t s v 1$ and reactions to Rice tungro spherical virus (RTSV) in various rice plants

\begin{tabular}{|c|c|c|c|}
\hline \multirow[b]{2}{*}{ Allele type } & \multirow[b]{2}{*}{ Nucleotide sequences 19,423 to 19,431 in AP005125 } & \multicolumn{2}{|c|}{ Plants examined for RTSV infection ${ }^{\mathrm{z}}$} \\
\hline & & Susceptible & Resistant \\
\hline S-type & TAT-GTT-GTT & $\begin{array}{l}\text { Nipponbare, TN1, Azucena, Swarna, } \\
\text { Pokkali, Matatag 2, Matatag 9, IR22, } \\
\text { IR24, IR46, IR64, Unkwang, UM80 } \\
\text { backcross lines (2), UM82 backcross } \\
\text { lines (10), UR backcross line (1) }\end{array}$ & $\ldots$ \\
\hline \multicolumn{4}{|l|}{ Non-S-type } \\
\hline UM-type & TGT-GCT-GTT & $\ldots$ & $\begin{array}{l}\text { UM82, UM82 backcross lines (13), } \\
\text { UM80 backcross lines (7), UR } \\
\text { backcross lines (2), Dongjin, } \\
\text { Matatag } 1\end{array}$ \\
\hline UR-type & TAT-GCT-GTT & $\ldots$ & $\begin{array}{l}\text { UR, UM80, UR backcross lines (2), } \\
\text { UM80 backcross lines (2) }\end{array}$ \\
\hline TKM6-type & TAT- - - -GTT or TAT-GTT- - - & $\ldots$ & TKM6, BR11 \\
\hline
\end{tabular}

${ }^{\mathrm{z}}$ Numbers in parentheses are those of independent lines. UM80, Utri Merah (accession number 16680); UM82, Utri Merah (accession number 16682); UR, Utri Rajapan; and TN1, Taichung Native 1. 
Chancellor 2002; Khush et al. 2004). The result of genetic analysis for RTSV resistance in this study was consistent with previous observations that resistance of Utri Merah to RTSV (strain A) is controlled by a single recessive gene, although additional genes in Utri Merah may also be involved in resistance against other strains of RTSV (Azzam et al. 2002; Ebron et al. 1994).

RTSV resistance gene $t s v 1$ from Utri Merah was mapped to a 200-kb region between 22.05 and $22.25 \mathrm{Mb}$ of chromosome 7. The $t s v 1$ region contains at least 30 expressed genes, including the gene for eIF4G ${ }^{t s v l}$ (Satoh et al. 2007). We selected the gene for eIF4G $\mathrm{G}^{t s v l}$ as a candidate gene for RTSV resistance based on previous reports that genes for eIF4E (Diaz-Pendon et al. 2004; Maule et al. 2007) and eIF4G (Yoshii et al. 2004; Albar et al. 2006; Boisnard et al. 2007) are involved in recessive resistance to plant viruses. In support of this candidacy is the fact that the eIF4G ${ }^{t s v l}$ gene is an ortholog of the eIF4G ${ }^{\text {cum } 2}$ gene of Arabidopsis thaliana, which is responsible for resistance to CMV and TCV (Yoshii et al. 2004; Boisnard et al. 2007). Examination for expression of genes within the $t s v 1$ region did not show any genes exhibiting significant differential expression after RTSV infection, except for a weak induction of expression of a gene encoding cyclin in both TN1 and TW16 only at $6 \mathrm{dpi}$. Thus, differential expression of genes around the $t s v 1$ region did not seem to play a key role in the expression of RTSV resistance.

In contrast, sequence comparison of the eIF4G ${ }^{t s v l}$ gene among Nipponbare, TN1, UM82, and TW16 identified unique sequence variants, $\mathrm{SNP}^{4387}$ and $\mathrm{SNP}^{4390}$, in the coding region sequenced, which were different between the susceptible and resistant plants. The S-type allele was found in all susceptible plants we examined. The non-S-type allele of the eIF4G ${ }^{t s v l}$ gene was further divided into three types but they are common, in that all three non-S-type alleles do not encode Val residue at amino acid position 1060 or 1061 of the predicted eIF4G ${ }^{t s v l}$ (Table 5), suggesting a functional relationship between the Val residues and susceptibility to RTSV. Because RTSV resistance can be confounded by resistance to GLH (Sebastian et al. 1996; Azzam and Chancellor 2002; Shibata et al. 2007; Zenna et al. 2008), the number of RTSV-resistant genotypes available for analysis in this study was limited. In this study, we have used all the available genotypes confirmed to be resistant to RTSV. The results of our survey for $\mathrm{SNP}^{4387}$ and $\mathrm{SNP}^{4390}$ among the available genotypes support the association of allelic variations of the eIF4G ${ }^{t s v l}$ gene with different reactions to RTSV infection. The allele types of eIF4G $\mathrm{G}^{t s v l}$ genes revealed in this study are consistent with previous observations on RTSV resistance. For example, RTSV resistance of UM80 and Utri Rajapan was controlled by the same allele of a single recessive gene (Ebron et al. 1994). Two RTD-resistant cultivars, Matatag 1 and Matatag 2, were derived from UM80 but only Matatag 1 is resistant to RTSV. Dongjin is a japonica rice cultivar with resistance to RSV. Resistance to RTSV and the presence of the UM-type allele in Dongjin, which is resistant to RSV, were unexpected, because Dongjin was developed in Korea, where RTSV has not been reported. Resistance to RSV was mapped to chromosomes 2 and 11 (Hayano-Saito et al. 2000; Maeda et al. 2006; Wu et al. 2009). It would be interesting to test whether RTSV resistance in Dongjin is conferred solely by the UM-type allele of the eIF4G ${ }^{t s v l}$ gene or partly contributed by RSV resistance.

Results from other experimental systems led us to speculate that the resistance in Utri Merah might have resulted from impaired translation of RTSV RNA with eIF4G ${ }^{t s v l}$. In protoplasts of the A. thaliana cum 2 mutant, the production of TCV and CMV proteins was reduced due to the negative effects of eIF $4 \mathrm{G}^{\text {cum } 2}$ mutation on the interaction between untranslated re- gions of viral RNA and eIF4G ${ }^{\text {cum2 }}$ (Yoshii et al. 2004). The mutant form of eIF4G ${ }^{\text {cum } 2}$ has only a single amino acid substitution ( Pro $^{1327}$ to $\mathrm{Cys}^{1327}$ ) compared with the corresponding wild-type eIF4G (Yoshii et al. 2004). The amino acid substitution in eIF4G ${ }^{\text {cum } 2}$ is between two domains characteristic of eIF4G, MIF4G, and MA3, whereas the mutation associated with RTSV resistance in eIF4G ${ }^{t s v l}$ is between the $\mathrm{NH}_{2}$-terminus and MIF4G domain (Fig. 4; Supplementary Fig. 2). eIF(iso)4G associated with RYMV resistance (eIF(iso) $4 \mathrm{G}^{\text {rymvl }}$ hereafter) is located on chromosome 4 of the rice genome (Albar et al. 2006). eIF(iso) $4 \mathrm{G}^{\text {rymvl }}$ (793 amino acids) is considerably shorter than eIF4G ${ }^{t s v l}\left(1,792\right.$ amino acids) and $\mathrm{eIF} \mathrm{G}^{\text {cum2 }}$ (1,723 amino acids) but aligns well with the $\mathrm{COOH}$-terminal half containing both MIF4G and MA3 domains of eIF4G ${ }^{t s v l}$ and eIF4G ${ }^{\text {cum } 2}$ (Fig. 4). The amino acid residues of eIF(iso) $4 G^{r y m v l}$ that were found substituted or deleted in rice cultivars resistant to RYMV reside within the MIF4G domain, and they are also highly conserved in eIF4G ${ }^{t s v l}$ and eIF4G ${ }^{\text {cum } 2}$. In contrast, the amino acid residues that are likely to be associated with virus susceptibility in eIF4G $\mathrm{G}^{t s v l}$ are not conserved in eIF $4 \mathrm{G}^{\text {cum } 2}$ or eIF(iso) $4 \mathrm{G}^{\text {rymvl }}$.

Some plant eIF4E proteins interact with the genome-linked viral proteins ( $\mathrm{Vpg}$ ) of Potyvirus spp., and this interaction is required for Potyvirus spp. to complete their infection processes (Schaad et al. 2000; Kang et al. 2005; Miyoshi et al. 2006; German-Retana et al. 2008). Disruption of the interaction between eIF4E and Vpg of Potyvirus spp. was suggested as an underlying mechanism for recessive virus resistance associated with eIF4E (Léonard et al. 2000; Yeam et al. 2007). Direct interactions of eIF4G and Vpg of RYMV and Turnip mosaic virus were also proposed (Miyoshi et al. 2006; Hébrand et al. 2008).

The inheritance of RTSV resistance in Utri Merah, the precise mapping of $t s v 1$, and sequence analysis of the eIF4G ${ }^{t s v l}$ gene among rice genotypes collectively suggested that the SNP in codons for Val ${ }^{1060-1061}$ of the predicted eIF4G ${ }^{t s v l}$ may be associated with RTSV resistance in rice plants. However, the involvement of other regions of the eIF4G ${ }^{t s v l}$ gene and of more than 30 genes located within the $t s v 1$ region in RTSV resistance cannot be excluded. Complementation and gene-specific silencing experiments are in progress to provide definite proof of the causal relationship between the SNP variants and resistance to RTSV.

\section{MATERIALS AND METHODS}

\section{Plant materials.}

Plant materials (individual plants and populations) used for genetic and gene expression analyses in relation to tungro virus infections are described in Figure 1. TW16 is a backcross line $\left(\mathrm{BC}_{5} \mathrm{~F}_{8}\right)$ developed from the donor cv. Utri Merah (IRGC accession number 16682) and the recurrent parent TN1. TN1 is susceptible to both RTSV and RTBV, whereas Utri Merah is resistant to RTSV. Near-isogenic lines $\left(\mathrm{BC}_{6} \mathrm{~F}_{4-5}\right)$ were developed by crossing TW16 and TN1 (Fig. 1). The $\mathrm{F}_{2}$ materials for mapping of RTSV resistance were derived from a cross between TW16-1120 (UM80-derived $\mathrm{BC}_{6} \mathrm{~F}_{4}$ line resistant to RTSV) and RTSV-susceptible japonica cv. Unkwang (Fig. 1). Rice plants examined for SNP of the eIF4G ${ }^{t s v l}$ gene listed in Table 5 were obtained at the International Rice Research Institute (IRRI). UM80-derived backcross lines, Matatag 1, and Matatag 2 were developed by crossing UM80 with various susceptible plants such as IR1561-228-3-3, IR22, IR44624127-1-2-2-3, IR64, and IR61009-37-2-1-2 (Khush et al. 2004). Utri Rajapan-derived lines were developed from crosses between Utri Rajapan (accession number 16684) and susceptible parents IR1561-228-3 and IR24 (Khush et al. 2004). Matatag 9 
was developed by an interspecific cross between RTD-resistant O. rufipogon and recurrent parent IR64 (Khush et al. 2004; Shibata et al. 2007).

Evaluation for RTSV resistance.

RTSV strain A (Cabauatan et al. 1995) maintained in TN1 was used as the source of inoculum. Insect inoculation of viruses to plants was done by the tube method as described by Cabauatan and associates (1995). GLH were given a 3-day acquisition access period to RTSV-infected plants and were allowed an inoculation access period of $24 \mathrm{~h}$ to 6- to 10-day-old plants at three insects per plant. Inoculated plants were maintained in the greenhouse of IRRI. Inoculated plants were evaluated for virus infection by ELISA (Cabauatan et al. 1995) at 14 or $21 \mathrm{dpi}$. The presence of RTSV in leaf extracts was determined by measurement of the absorbance at $405 \mathrm{~nm}$ using an ELISA reader (BioTek Instruments, Winooski, VT, U.S.A.). Plants for which the 10-fold diluted extracts exhibited an absorbance value greater than 0.1 were considered infected with RTSV. At least 20 individual plants for each cultivar or $\mathrm{F}_{3}$ family were evaluated for RTSV infection. $\mathrm{F}_{3}$ families with an infection rate of $<20 \%$ were classified as resistant to RTSV, 21 to $79 \%$ as segregating, and $>80 \%$ as susceptible.

\section{Genotyping.}

DNA was extracted from leaf samples of approximately 3 $\mathrm{cm}$ from individual plants. DNA extraction was done using the minipreparation cetyltrimethylammonium bromide method. A polymorphism survey was conducted with SSR markers, which cover all 12 rice chromosomes. Each PCR reaction was carried out in a total volume of $20 \mu \mathrm{l}$ with an MJ PTC-100 (MJ Research, Watertown, MA, U.S.A.) thermocycler. PCR was performed at $94^{\circ} \mathrm{C}$ for $4 \mathrm{~min}$ for initial denaturation; followed by 35 cycles at $94^{\circ} \mathrm{C}$ for $1 \mathrm{~min}$ for denaturation, $55^{\circ} \mathrm{C}$ for 1 min for annealing, and $72^{\circ} \mathrm{C}$ for 2 min for extension; and then a final extension step at $72^{\circ} \mathrm{C}$ for $7 \mathrm{~min}$ before cooling to $4^{\circ} \mathrm{C}$. For some SSR primers, the annealing temperature was modified in the range of 50 to $60^{\circ} \mathrm{C}$ to improve the amplification.

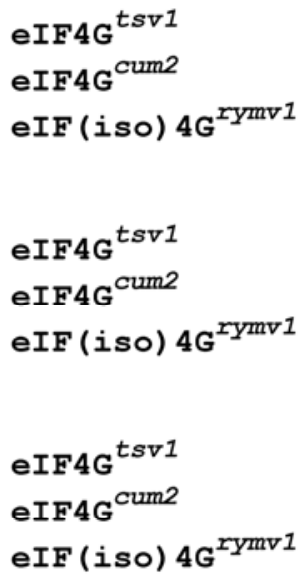

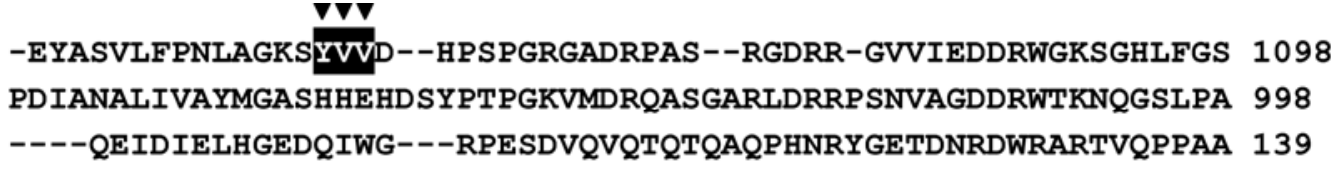

Fig. 4. Alignment of MIF4G domain sequences among eIF $4 \mathrm{G}^{t s v l}$, eIF $4 \mathrm{G}^{\text {cum }}$, and eIF(iso) $4 \mathrm{G}^{\text {rymvl }}$ and the locations of amino acid residues substituted or deleted in plants resistant to viruses. The sequences corresponding to the MIF4G domain are highlighted in gray. Amino acid sequences of eIF4G $\mathrm{G}^{t s v l}$ (based on transcript NP_001059958.1 [LOC_Os07g36940.1]) and eIF(iso)4G ${ }^{r y m v l}$ (based on transcript NP_001053219.1 [LOC_Os04g42140.1]) are from rice cv. Nipponbare. The amino acid sequence of eIF4G ${ }^{\text {cum } 2}$ (based on AT3G60240.2 [AT3G60240.2-TAIR]) is from Arabidopsis thaliana ecotype Columbia. Amino acid residues to be substituted or deleted in virus-resistant plants (Yoshii et al. 2004; Albar et al. 2006) are indicated by black boxes and triangles. Similarity of amino acid residues is indicated as $*=$ identical, $:=$ conserved substitutions, and.$=$ semiconserved substitution (similar shapes). 
Amplified products were run on $1.4 \%$ agarose gel or $12 \%$ polyacrylamide gel for visual scoring of marker polymorphisms.

\section{Microarray.}

The expression of genes located at $t s v 1$ in response to RTSV infection in TN1 and TW16 was examined by microarray analysis. Five seedlings per pot $(12 \mathrm{~cm}$ in diameter) of the respective plants were grown in a temperature-controlled greenhouse $\left(27\right.$ to $\left.29^{\circ} \mathrm{C}\right)$. Nine-day-old seedlings were inoculated with RTBV or RTSV as described above. Corresponding control (mock-inoculated) plants for RTBV- or RTSV-inoculated plants were also prepared. RNA samples were prepared from leaf samples pooled from three to five plants of the same treatment with the RNeasy Maxi kit (Qiagen, Valencia, CA, U.S.A.) according to the manufacturer's instructions. Comparisons of gene expression patterns were made between TN1 (or TW16) inoculated with RTSV and the corresponding mock-inoculated plants. A custom oligonucleotide microarray printed with 60-mer oligonucleotides deduced from approximately 43,500 full-length cDNA clones from rice cv. Nipponbare (Satoh et al. 2007) was employed for the analysis. Labeling of RNA samples, processing of microarray slides, and data analysis were performed as previously described (Satoh et al. 2007). The experiments were repeated three times. If $P$ values for the difference in expression intensities of a gene between RTSV-infected and mock-inoculated plants were $<0.05$, the gene was declared to be differentially expressed. The microarray data used in this study (series number GSE16142) are available at the National Center for Biotechnology Information (NCBI) Gene Expression Omnibus database.

\section{Sequence analysis.}

Genomic DNA sequences for a part of LOC_Os7g36940 (gene for eIF4G $\mathrm{G}^{t s v l}$ ) corresponding to nucleotide positions from 16,965 to 22,421 of BAC clone AP005125 (Fig. 3) in TN1, UM82, and TW16 were determined by primer walking based on the corresponding sequences in the Nipponbare genome by Macrogen Inc. (Seoul, Korea). The sequences were available at NCBI GenBank (accession numbers GQ203288, GQ203289, and GQ203290). DNA fragments containing $\mathrm{SNP}^{4387}$ and $\mathrm{SNP}^{4390}$ sites were amplified by PCR from genomic DNA of the plants listed in Table 5 with primers $5^{\prime}$ TAATGCATACAAGGGACCTG-3' and 5'-CTGCTTTGTG CATTACTTGC-3'. The resultant DNA fragment of approximately 630 bp was cloned in pGEM-T Easy vector (Promega Corp., Madison, WI, U.S.A.) and sequenced by Macrogen Inc. Information on the rice genome sequences at $t s v 1$ was obtained from the databases of NCBI GenBank, Michigan State University's Rice Genome Annotation Project, and Gramene. Information on cDNA molecules for the eIF4G ${ }^{t s v l}$ gene referred to the Rice Annotation Project Database. Protein sequences used for alignment were derived from the following cDNA sequences available at Gramene: NP_001059958.1 (LOC_Os07g36940.1) for eIF4G ${ }^{t s v l}$, NP_001053219.1 (LOC_Os04g42140.1) for eIF(iso) $4 \mathrm{G}^{\text {rymv }}$, and AT3G60240.2 (AT3G60240.2-TAIR) for eIF4G ${ }^{\text {cum } 2}$. Nucleotide and protein sequence alignments were performed by the ClustalW2 program.

\section{ACKNOWLEDGMENTS}

This work was supported in part by International Collaborative Research Funds from the Rural Development Administration, Korea, and a Basic Research Activities for Innovative Biosciences grant from the Biooriented Technology Research Advancement Institution, Japan. We thank Dr. Bill Hardy for editing the manuscript, Setsuko Kimura for supporting the microarray experiment, and the Japan-IRRI project for providing TW16 used in this study.

\section{LITERATURE CITED}

Albar, L., Bangratz-Reyser, M., Hébrand, E., Ndjiondjop, M.-N., Jones, M., and Ghesquière, A. 2006. Mutations in the eIF(iso)4G translation initiation factor confer high resistance to rice to Rice yellow mottle virus. Plant J. 47:417-426.

Angeles, E. R., and Khush, G. S. 2000. Genetic analysis of resistance to green leafhopper, Nephotettix virescens (Distant), in three varieties of rice. Plant Breed. 119:446-448.

Azzam, O., and Chancellor, T. C. B. 2002. The biology, epidemiology, and management of rice tungro disease in Asia. Plant Dis. 86:88-100.

Azzam, O., Imbe, T., Ikeda, R., Nath, P. D., and Coloquio, E. 2001. Inheritance of resistance to rice tungro spherical virus in a near-isogenic line derived from Utri Merah and in rice cultivar TKM6. Euphytica 122:9197.

Boisnard, A., Albar, L., Thiemele, D., Rondeau, M., and Ghesquiere, A. 2007. Evaluation of genes from $e I F 4 E$ and $e I F 4 G$ multigenic families as potential candidates for partial resistance QTLs to Rice yellow mottle virus in rice. Theor. Appl. Genet. 116:53-62.

Cabauatan, P. Q., Kobayashi, N., Ikeda, R., and Koganezawa, H. 1993. Oryza glaberrima: an indicator plant for rice tungro spherical virus. Int J. Pest Manage. 39:273-276.

Cabauatan, P. Q., Cabunagan, R. C., and Koganezawa, H. 1995. Biological variants of rice tungro viruses in the Philippines. Phytopathology 85:7781.

Cabunagan, R. C., Angeles, E. R., Villareal, S., Azzam, O., Teng, P. S., Khush, G. S., Chancellor, T. C. B., Tiongco, E. R., Truong, X. H., Mancao, S., Astika, I. G. N., Muis, A., Chowdhury, A. K., Narasimhan, V., Ganapathy, T., and Subramanian, N. 1999. Multilocation evaluation of advanced breeding lines for resistance to rice tungro viruses. Pages 45-55 in: Rice Tungro Disease Management. T. C. B. Chancellor, O. Azzam, and K. L. Heong, eds. International Rice Research Institute, Manila, Philippines.

Dahal, G., Hibino, H., Cabunagan, R. C., Tiongco, E. R., Flores, Z. M., and Aguiero, V. M. 1990. Changes in cultivar reaction to tungro due to changes in "virulence" of the leafhopper vector. Phytopathology 80:659-665.

Diaz-Pendon, J. A., Truniger, V., Nieto, C., Gracia-Mas, J., Bendahmane, A., and Aranda, M. A. 2004. Advances in understanding recessive resistance to plant viruses. Mol. Plant Pathol. 5:223-233.

Ebron, L. A., Yumol, R. R., Ikeda, R., and Imbe, T. 1994. Inheritance of resistance to rice tungro spherical virus in some rice cultivars. Int. Rice Res. Notes 19:10-11.

Encabo, J. R., Cabauatan, P. Q., Cabunagan, R. C., Satoh, K., Lee, J.-H., Kwak, D.-Y., De Leon, T. B., Macalalad, R. J. A., Kondoh, H., Kikuchi, S., and Choi, I.-R. 2009. Suppression of two tungro viruses in rice by separable traits originating from cultivar Utri Merah. Mol. Plant-Microbe Interact. 22:1268-1281.

Fauquet, C. M., Mayo, M. A., Maniloff, J., Desselberger, U., and Ball, L. A. 2005. Virus Taxonomy. Eighth Report of the International Committee for the Taxonomy of Viruses. Academic Press, New York.

German-Retana, S., Walter, J., Doublet, B., Roudet-Tavert, G., Nicaise, V., Lecampion, C., Houvenaghel, M.-C., Robigalia, C., Michon, T., and Le Gall, O. 2008. Mutational analysis of plant cap-binding protein eIF4E reveals key amino acids involved in biochemical functions and Potyvirus infection. J. Virol. 82:7601-7612.

Hayano-Saito, Y., Saito, K., Nakamura, S., Kawasaki, S., and Iwasaki, M. 2000. Fine physical mapping of the rice stripe resistance gene locus, Stvb-i. Theor. Appl. Genet. 101:59-63.

Hébrand, E. Galzi-Pinel, A., and Fargette, D. 2008. Virulence domain of the RYMV genome linked viral protein VPg towards rice rymv1-2-mediated resistance. Arch. Virol. 153:1161-1164.

Hibino, H. 1983. Relations of rice tungro bacilliform and rice tungro spherical viruses with their vector Nephotettix virescens. Annu. Phytopathol. Soc. Jpn. 49:545-553.

Hibino, H. 1996. Biology and epidemiology of rice viruses. Annu. Rev. Phytopathol. 34:249-273.

Hibino, H., Daquiaog, R. D., Cabauatan, P. Q., and Dahal, G. 1988. Resistance to rice tungro spherical virus in rice. Plant Dis. 72:843-847.

Hibino, H., Daquiaog, R. D., Mesina, E. M., and Aguiero, V. M. 1990. Resistances in rice to tungro-associated viruses. Plant Dis. 74:923-926.

Imbe, T., Ikeda, R., Kobayashi, N., Ebron, L. A., Yumol, R. R., Bautista, N. S., and Tambien, R. E. 1995. Genetic studies in relation to breeding rice varieties resistant to tungro disease. In: The Development of Stabilization Technology for Double Cropping in the Tropics. Final Report of the IRRI-Government of Japan Collaborative Research Project. Manila, The Phillipines.

Kang, B.-C., Yeam, I., Frantz, J. D., Murphy, J. F., and Jahn, M. 2005. The pvrl locus in Capsicum encodes a translation initiation factor eIF4E that interacts with Tobacco etch virus VPg. Plant J. 42:392-405. 
Khush, G. S., Angeles, E., Virk, P. S., and Brar, D. S. 2004. Breeding rice for resistance to tungro virus at IRRI. SABRAO J. Breed. Genet. 36:101-106.

Léonard, S., Plante, D., Wittmann, S., Daigneault, N., Fortin, M. C., and Lalibereté, J.-F. 2000. Complex formation between Potyvirus Vpg and translation eukaryotic initiation factor 4E correlates with virus infectivity. J. Virol. 74:7730-7737.

Maeda, H., Matsushita, K., Iida, S., and Sunohara, Y. 2006. Characterization of two QTLs controlling resistance to Rice stripe virus detected in a Japanese upland rice line Kanto 72. Breed. Sci. 56:359-364.

Maule, A. J., Caranta, C., and Boulton, M. I. 2007. Sources of natural resistance to plant viruses: status and prospects. Mol. Plant Pathol. 8:223231.

Miyoshi, H., Suehiro, N., Tomoo, K., Muto, S., Takahashi, T., Tsukamoto, T., Ohmori, T., and Natsuaki, T. 2006. Binding analyses for the interaction between plant virus genome-linked protein ( $\mathrm{VPg})$ and plant translational initiation factors. Biochemie 88:329-340.

Olsen, A. N., Ernst, H. A., Leggio, L. L., and Skriver, K. 2004. NAC transcription factors: structurally distinct, functionally diverse. Trends Plant Sci. 10:1360-1385.

Rice Full-Length cDNA Consortium. 2003. Collection, mapping, and annotation of over 28,000 cDNA clones from japonica rice. Science 301:376-379.

Satoh, K., Doi, K., Nagata, T., Kishimoto, N., Suzuki, K., Otomo, Y., Kawai, J., Nakamura, M., Hirozane-Kishikawa, T., Kanagawa, S., Arakawa, T., Takahashi-Iida, J., Murata, M., Ninomiya, N., Sasaki, D., Fukuda, S., Tagami, M., Yamagata, H., Kurita, K., Kamiya, K., Yamamoto, M., Kikuta, A., Bito, T., Fujitsuka, N., Ito, K., Kanamori, H., Choi, I.-R., Nagamura, Y., Matsumoto, T., Murakami, K., Matsubara, K., Carninci, P., Hayashizaki, Y., and Kikuchi, S. 2007. Gene organization in rice revealed by full-length cDNA mapping and gene expression analysis through microarray. PLoS ONE 2:e1235.

Schaad, M. C., Anderberg, R. J., and Carrington, J. C. 2000. Strain-specific interaction of the tobacco etch virus NIa protein with the translation initiation factor eIF4E in the yeast two hybrid system. Virology 234:84-92.

Sebastian, L. S., Ikeda, R., Huang, N., Imbe, T., Coffman, W. R., and
McCouch, S. R. 1996. Molecular mapping of resistance to rice tungro spherical virus and green leafhopper in rice. Phytopathology 86:25-30.

Shahjahan, M., Jalant, A. H., Zakri, A. H., Imbe, T., and Othman, O. 1990. Inheritance of tolerance to rice tungro bacilliform virus (RTBV) in rice (Oryza sativa L.). Theor. Appl. Genet. 80:513-517.

Shibata, Y., Cabunagan, R. C., Cabauatan, P. Q., and Choi, I.-R. 2007. Characterization of Oryza rufipogon-derived resistance to tungro disease in rice. Plant Dis. 91:1386-1391.

Wu, S.-J., Zhong, H., Zhou, Y., Zuo, H., Zhou, L-H., Zhu., J.-Y., Ji, C.-Q., Gu, S.-L., Gu, M.-H., and Liang, G.-H. 2009. Identification of QTLs for the resistance to rice stripe virus in indica rice variety Dular. Euphytica 165:557-565.

Yeam, I., Cavatorta, J. R., Ripoll, D. R., Kang, B.-C., and Jahn, M. M. 2007. Functional dissection of naturally occurring amino acid substitutions in eIF4E that confers recessive Potyvirus resistance in plants. Plant Cell 19:2913-2928.

Yoshii, M., Nishikiori, M., Tomita, K., Yoshioka, N., Kozuka, R., Naito, S., and Ishikawa, M. 2004. The Arabidopsis Cucumovirus Multiplication 1 and 2 loci encode translation initiation factors $4 \mathrm{E}$ and $4 \mathrm{G}$. J. Virol. 78:6102-6111.

Yoshii, M., Shimizu, T., Yamazaki, M., Higashi, T., Miyao, A., Hirochika H., and Omura, T. 2009. Disruption of a novel gene for a NAC-domain protein in rice confers resistance to Rice dwarf virus. Plant J. 57:615625.

Zenna, N. S., Cabauatan, P. Q., Baraoidan, M., Leung, H., and Choi, I.-R 2008. Characterization of a putative rice mutant for reaction to rice tungro disease. Crop Sci. 48:480-486.

\section{AUTHOR-RECOMMENDED INTERNET RESOURCES}

Michigan State University's Rice Genome Annotation Project website: rice.plantbiology.msu.edu

Gramene database: www.gramene.org

Rice Annotation Project database: rapdb.dna.affrc.go.jpp

European Molecular Biology Laboratory-European Bioinformatics Institute's ClustalW2 program: www.ebi.ac.uk/Tools/clustalw2 